\title{
¿Traición o innovación? La influencia europea en la creación literaria del escritor chino contemporáneo Yan Lianke
}

\section{Betrayal or Innovation? European Influence on the Literary Creation of the Contemporary Chinese Writer Yan Lianke}

\author{
Taciana Fisac ${ }^{1}$ \\ Universidad Autónoma de Madrid (España)
}

Recibido: 01-07-18

Aprobado: 31-07-18

\section{Resumen}

La traducción de textos, muchos de ellos procedentes de Europa, ha tenido un protagonismo especial en algunos momentos de la historia de China. Uno de ellos se produce en la década de los 80 del siglo XX -y se extiende aún hasta nuestros días- con la publicación de innumerables libros extranjeros, influenciando a su vez la escritura literaria china. Yan Lianke (1958- ) es un ejemplo paradigmático de un autor chino que admite públicamente el impacto de la literatura extranjera en sus novelas. Ahora bien, ¿hasta qué punto es esa influencia cierta? Mediante el análisis de algunas obras de Yan Lianke, tanto de narrativa como de teoría literaria, se tratará de valorar el alcance de dicha influencia y los rasgos característicos de la misma.

Palabras-clave: China, Europa, literatura, traducción, Yan Lianke.

\footnotetext{
${ }^{1}$ (taciana.fisac@uam.es). Catedrática con especialidad en lengua y literatura chinas, directora del Centro de Estudios de Asia Oriental de la Universidad Autónoma de Madrid. Este trabajo forma parte del proyecto EAU-TBC (HERA.15.066), financiado por el Ministerio de Economía, Industria y Competitividad y la Unión Europea a través del programa HERA JRP-UP. Catedrática honorífica de la Universidad de Estudios Extranjeros de Pekín, Premio Especial del Libro de China 2012. Investigadora visitante, entre otras, en las universidades de Stanford, Oxford, Leiden, Carolina del Norte y Ohio State, en la Academia China de Ciencias Sociales, Universidad de Pekín y Hong Kong Open University. Ha publicado extensamente sobre literatura y sociedad en China. Su última traducción es Los cuatro libros de Yan Lianke.
} 


\begin{abstract}
The encounter between Europe and China has historically produced several watershed moments marked by tides of translation. Many of the texts translated from European languages have played a special role in China's literary development. The wave of publication of a vast array of foreign books that started in the 1980s and in a sense is ongoing in the present day has had a profound impact on the Chinese writing and literary culture. Yan Lianke (b. 1958) is a paradigmatic example of a Chinese author who publicly acknowledges the influence of foreign literature on his novels. By means of an analysis of the inflections of European literary motives in Yan Lianke's novels and theoretical works, we can begin to take stock of the scope and modes of this influence.
\end{abstract}

Key-words: China, Europe, literature, translation, Yan Lianke.

El encuentro entre China y Europa tuvo cierto auge entre los siglos XVI y XVIII, protagonizado entonces por letrados chinos y diversas órdenes religiosas extranjeras, entre las cuales destacaría la Compañía de Jesús. Pero fue, fundamentalmente, a finales del siglo XIX e inicios del XX cuando, tras varios conflictos bélicos y la apropiación territorial por parte de diversas potencias coloniales, China se embarca en un intercambio más extenso y de mayor calado social e intelectual con Europa. Muchos estudiosos y escritores chinos se sienten atraídos por la ciencia y la tecnología, así como por corrientes de pensamiento extranjeras, y se inicia una masiva traducción al chino de un corpus sumamente rico y variado. En el mismo se busca encontrar inspiración para la renovación de ideas y formas literarias, al tiempo que una respuesta a la crisis social y política de la época. La cultura europea -junto con la norteamericana- va a ocupar multitud de páginas en las revistas más conocidas de la nueva era republicana china. Algunos textos son traducidos directamente al chino, otros, a través de lenguas intermedias, entre las cuales destacarán el japonés y, más adelante, el ruso. Es así como se produce un diálogo con nuevos tropos y sentidos del mundo europeo, que se adaptan, discuten y reinterpretan a la luz de la idiosincrasia sociopolítica de la China de entonces.

Ahora bien, ¿hasta qué punto las traducciones de textos trasladan realmente el pensamiento europeo? Generalmente se pone un enorme énfasis en las ideas originales que se vierten a otras lenguas, pero las lecturas de textos traducidos nos invitan a entender que, en el acto de trasplantar un texto a otro paradigma linguístico, independientemente de la actitud que toma el traductor o intermediario, muchas veces también se produce una suerte de recreación o nueva creación. Además, cuando el traductor tiene una incorrecta comprensión, 
se aleja de las ideas originales del texto o incluso las modifica conscientemente, puede llevar a interpretaciones erróneas y malentendidos que, paradójicamente, quizá resulten fértiles para otros creadores o lectores. La utilización y modificación de traducciones con fines muy concretos no ha sido una excepción en la historia de China. Mientras a partir del siglo XVI los jesuitas adaptaban las fábulas europeas tradicionales con fines evangélicos, a finales del XIX e inicios del XX, un conocido activista e intelectual chino, Liang Qichao (18731929), abogaba por la traducción de literatura para la renovación de las ideas y la causa política ${ }^{2}$. La propia selección de los libros que se han traducido bien pudieran considerarse una primera "manipulación" del texto y sus fines, pero la realidad nos ofrece pistas para entender que también concurren situaciones muy peculiares en la elección de los textos y la agenda no siempre está tan bien definida como pudiera imaginarse ${ }^{3}$.

Por otra parte, la ilusión de una plena traducción de un texto literario a otra lengua resulta evidente cuando se lee la traducción de una obra maestra de la literatura originalmente escrita en la lengua materna del lector. Para un español, la lectura de El ingenioso hidalgo Don Quijote de la Mancha en chino, en cualquier de sus numerosas versiones, hace evidente la intraducibilidad del texto. Lo mismo sucede a un lector chino con Sueño en el Pabellón Rojo, la gran novela china del siglo XVIII, cuyas abundantes metáforas y alegorías, homofonías y dilogías, imágenes y símbolos, poemas y paralelismos originales se pierden en su traducción a la lengua española.

En el caso de China, hubo traductores famosos que realizaron versiones directas y otros se acercaron a los textos a través de lenguas intermedias $\mathrm{u}$ otros medios. Así, Yan Fu (1853-1921), uno de los más famosos traductores de su época, conocía el inglés y tradujo textos de Huxely, J. S. Mill y otros muchos pensadores europeos. Ma Junwu (1882-1939), formado en Japón y en Alemania, tradujo del japonés varios libros, entre otros, Sobre el origen de las especies de Darwin, además de obras del alemán o del inglés. Por su parte, Su Manshu (1884-1918) introducía a poetas y literatos como Byron, Schiller o Goethe. En el capítulo de los famosos traductores desconocedores de cualquier lengua extranjera, destaca el caso de Lin Shu (1852-1924) que recreó en chino clásico, entre otros, textos procedentes de Inglaterra, Francia, Rusia, Suiza, Bélgica, España y Noruega con ayuda de numerosos intérpretes chinos ${ }^{4}$.

${ }^{2}$ Véase Sher-Shiueh Li, “The Art of Misreading: An Analysis of the Jesuit 'Fables' in Late Ming China” pp. 71-94 y Luo Xuanmin, "Ideology and Literary Translation. A Brief discussion on Liang Qi-chao's Translation Practice”, pp. 124-134 [en Luo Xuanmin y He Yuanjian (eds.), Translating China, Bristol, Buffalo, Toronto, Multilingual Matters, 2009].

${ }^{3}$ En los años 80 del siglo XX, una de las primeras novelas españolas que se tradujeron al chino fue Yo soy fulana de tal de Álvaro de Laiglesia. En un encuentro casual con el traductor, aclaró que la selección se debió a una propuesta de un español, por ser una novela de humor con éxito de ventas.

4 Véase Ma Zuyi "History of Translation in China", pp. 373-392, [en Chan Sin-Wai y David E. Pollard (eds) An Encyclopedia of Translation, Hong Kong, The Chinese University Press, 2001]. 
De entre los miles de estudiantes chinos que a principios del siglo XX fueron a cursar carreras en el exterior del país, muchos aportaron su grano de arena para dar a conocer, a través de la traducción, las corrientes de pensamiento extranjeras, incluyendo, naturalmente, aquellas que se difundirían tras la Revolución Rusa de 1917. Pero además, en las primeras décadas del siglo pasado se publican libros y artículos que tratan de dar a conocer la historia del pensamiento y de la literatura del mundo, en especial, del denominado “mundo occidental". Así, Zhou Zuoren (1885-1967), hermano del escritor Lu Xun (1881-1936), además de traducir, tras su nombramiento como profesor en la Universidad de Pekín, escribe la primera obra en la cual se introduce de un modo más sistemático la literatura del continente europeo. Su libro, Historia de la literatura europea (Ouzhou Wenxue Shi), nace como material para impartir las clases que se le asignan. Comienza el borrador del texto en septiembre de 1917 y lo finaliza el 8 de junio de 1918, publicándose apenas cuatro meses más tarde. Se trata de un estudio breve para el alcance que abarca, puesto que en el mismo se hace un recorrido por autores y obras literarias importantes en Europa, desde el mundo clásico griego, pasando por Roma, la literatura medieval, el Renacimiento y capítulos específicos sobre el siglo XVII para la literatura francesa, inglesa, alemana, Europa del Norte y del Sur, así como una escueta mención a corrientes del inicio del siglo XIX. Las obras del mundo clásico griego (páginas 3 a 64) y romano (67 a 121) ocupan la mayoría de un total de 199 páginas, concretamente, desde la 3 a la 121 en la edición a la que se ha tenido acceso. A modo de ejemplo, en el apartado de la literatura española se mencionan trece autores, cuyos nombres aparecen a lo largo del libro en el siguiente orden: Guevara, Jorge de Montemayor, Diego Hurtado de Mendoza, Mateo Alemán, Francisco Quevedo, Miguel de Cervantes y Saavedra, Luis de Góngora, Lope de Vega, Pedro Calderón, Vicente Espinel, Ignacio de Luzán, José de Hervás (referido a José Gerardo de Hervás) y Benito Feijóo. Destacan también numerosas menciones a la picaresca y alguna al culteranismo, mientras que la obra en lengua española a la cual se dedica más extensión es El Quijote ${ }^{5}$. Años después, en 1929 y 1934, su hermano Lu Xun introduce también a Pío Baroja, autor de la generación del 98, con la traducción de relatos y breves obras teatrales ${ }^{6}$. No son estos los únicos escritores españoles que se dan a conocer en China, pero valgan como muestra de los nombres y corrientes que se mencionan a inicios del siglo XX respecto a la tradición literaria española.

\footnotetext{
${ }^{5}$ Versión consultada: Zhou Zuoren, Ouzhou Wenxue Shi [Historia de la literatura europea], Beijing, Shiyue Wenyi Chubanshe, 2013. Las menciones a la literatura española aparecen en las páginas 148$149 ; 159-161$ y 179.

${ }^{6}$ Lennart Lundberg, Lu Xun as a Traslator: Lu Xun's translation and introduction of literature and literary theory, 1903-1936, Stockholm, Orientaliska Studier Stockholm University, 1989, pp. 158-160.
} 
La primera mitad del siglo XX en China se corresponde con un periodo enormemente rico en debates, al tiempo que complejo y convulso para la sociedad. La fundación de la República Popular China en 1949 va a suponer la ruptura con el anterior pluralismo de ideas. El protagonismo exclusivo del marxismo-leninismo -una ideología también procedente de Europa- junto con el pensamiento de Mao Zedong, supondrá de hecho un paréntesis en el diálogo con el exterior. Una de las características del periodo maoísta es el aislamiento y la resistencia a dar cabida a cualquier influencia extranjera, especialmente después de la crisis con la Unión Soviética de los años 50 y durante la Revolución Cultural, coincidiendo oficialmente su finalización en 1976 con el año de la muerte del Gran Timonel.

A partir de los años 80, aparece de nuevo en escena el fenómeno de la traducción de textos extranjeros al chino; diríase que se vuelve a recuperar parte del espíritu que había motivado a los escritores del conocido como Movimiento de la Nueva Cultura o, también llamado Movimiento del 4 de mayo de 1919. La traducción de textos literarios extranjeros al chino o revistas como Waiguo Wenyi (Literatura y Arte Extranjeras) y Shijie Wenxue (Literatura Universal) ${ }^{7}$ y otras, establecidas en ciertos casos como revistas para uso interno del Partido y posteriormente para el gran público, revitalizan la escena literaria china a partir de 1978, al tiempo que reavivan algunos de los debates del pasado. Esta apertura no tiene únicamente un carácter literario, sino también político. De hecho en este primer periodo los politólogos occidentales seguían el acontecer en el mundo literario chino para tratar de identificar el alcance de los cambios y los nuevos límites aceptados. No en vano el periodo maoísta había supuesto uno de los más duros totalitarismos de la historia.

En el ámbito estrictamente literario, a partir de ese momento, raro será que los estudiosos chinos o extranjeros no resalten en los autores chinos la influencia de corrientes literarias extranjeras, muchas de ellas europeas. Así, por ejemplo, se subraya la influencia de autoras como Virginia Woolf y su stream of consciousness en Wang Meng ${ }^{8}$ o se pone de manifiesto la influencia de Kafka, Joyce, Sartre, Ionesco o Kundera, entre otros muchos representantes de las vanguardias literarias europeas, o García Márquez, como figura privilegiada del boom latinoamericano. Esta tendencia se perpetuará durante bastante tiempo. Incluso, en algunos casos se subraya como única fuente de inspiración el realismo mágico latinoamericano, si bien existen elementos en el seno de la propia tradición literaria china en donde conviven seres del más allá

\footnotetext{
${ }^{7}$ Meng Fanhua, Cheng Guangwei y Chen Xiaoming, Zhongguo Dandai Wenxue Liushi Nian [Sesenta Años de Literatura China Contemporánea], Beijing, Beijing Daxue Chubanshe, 2015; pp. 132 y ss.

${ }^{8}$ Leo Ou-Fan Lee, "The Politics of Technique: Perspectives of Literary Dissidence in Contemporary Chinese Fiction", pp. 159-190, [en Jeffrey C. Kinkley (ed.) After Mao: Chinese Literature and Society 1978-1981, Cambridge (Massachusetts) y London, The Council on East Asian Studies/Harvard University, 1985].
}

Araucaria. Revista Iberoamericana de Filosofia, Política, Humanidades y Relaciones Internacionales, año 20, $\mathrm{n}^{\circ} 40$ Segundo semestre de 2018. Pp. 137-158. ISSN 1575-6823 e-ISSN 2340-2199 doi: 10.12795/araucaria.2018.i40.06 
y del más acá, como son los cuentos de la transmisión de lo extraordinario o chuanqi, un género narrativo que florece durante la dinastía Tang (618-907), en el que se narran tanto hechos cotidianos como extraños y sorprendentes. Ese es, por ejemplo, el caso de Mo Yan, galardonado en 2012 con el premio Nobel de literatura, que en una entrevista muy anterior cuenta el impacto e indignación que le produjo la lectura de las novelas de García Márquez. Impacto, porque le sirvió para cuestionar sus propias experiencias, e indignación, porque presintió que aquellos textos bien hubieran podido salir de la pluma de un autor chino, dando lugar a un "García Márquez chino". Mo Yan afirmaba haber tratado de alejarse de su influencia para escribir su famosa novela Sorgo rojo, y sostenía que los escritores chinos podían transformar y desarrollar un estilo propio en un diálogo con la literatura universal ${ }^{9}$. De hecho, en su discurso ante la Academia Sueca con motivo de la concesión del premio Nobel, admitía su admiración por Faulkner y García Márquez, sin renegar de su posible influencia, pero reivindicaba la existencia de una suerte de realismo mágico propio de la tradición china, y no le faltaba razón para hacer tal afirmación ${ }^{10}$.

En cualquier caso, todo este debate pone de manifiesto la enorme importancia que ha tenido la traducción en la China moderna y sigue teniendo en el periodo contemporáneo. Hoy en día, en la visita a cualquier librería, sorprende el ingente número de textos extranjeros clásicos, modernos y contemporáneos que se exponen en las vitrinas. Algunos son reimpresiones de traducciones pasadas, otros son producto de la promoción que el Ministerio de Cultura de la República Popular China ha realizado en los últimos años, tanto para publicación de literatura china a otras lenguas como de libros extranjeros al chino. Se han vertido al chino obras que abarcan desde los clásicos griegos hasta los grandes pensadores europeos del siglo XIX y XX, y en las últimas tendencias también se ha dado importancia a la traducción de los trabajos de sinólogos y especialistas extranjeros sobre China. Tanto su variedad como su volumen puede llevar a cuestionar si no serán necesarias varias décadas para poder digerir razonablemente tal cúmulo de conocimientos. Y de nuevo surge la cuestión de la calidad de las traducciones. En cualquier caso, no se puede discutir que China tiene acceso y se interesa por múltiples ideas y corrientes de pensamiento surgidas en el continente europeo.

\footnotetext{
${ }^{9}$ Laifong Leung, Morning Sun. Interviews with Chinese Writers of the Lost Generation, Armonk, London, M. E. Sharpe, 1994, pp. 150-151.

10 Veáse https://www.nobelprize.org/nobel_prizes/literature/laureates/2012/yan-lecture.html. [acceso el 22 de mayo 2018]. El discurso de Mo Yan aparece en varias lenguas que tienen diferencias de matices con respecto al original chino.
} 


\section{Literatura europea y escritura china: el caso de Yan Lianke}

Las bibliotecas de los escritores chinos contemporáneos también cuentan con numerosas obras de autores extranjeros. Así se confirma en muchas conversaciones, tanto con estudiosos chinos de la literatura contemporánea como con los propios autores. Algunos reconocen abiertamente que han encontrado inspiración en fuentes literarias procedentes del exterior, y de entre estos, Yan Lianke es probablemente quien lo expresa de manera más abierta. En boca del mismo autor: "Si digo que la influencia de la literatura extranjera ha sido mayor en mí que la de la literatura china, no sé si habrá quien me insulte, me tache de vendido y traidor a China, pero la situación es cierta, es así"11. Ahora bien, ¿hasta qué punto es real esta afirmación del propio Yan Lianke? ¿Cuál es el alcance de esta influencia extranjera? ¿Pueden identificarse elementos de origen foráneo y propios de la tradición china en su escritura? El análisis que sigue tratará de dar algunas respuestas iniciales a estas cuestiones.

Yan nació en un pequeño pueblo de la provincia de Henan, el mismo año en el que se lanzaba el Gran Salto Adelante. Aquellos eran tiempos de grandes movilizaciones políticas, y sus padres, humildes campesinos, nunca celebraron su cumpleaños. Cuando con veinte años acude a alistarse en el Ejército, al preguntarle la fecha de su nacimiento se puso de manifiesto su desconocimiento de la misma. Tras algunas consideraciones sobre el tiempo y las circunstancias de la época, que Yan había conocido a través de su familia, el responsable decidió inscribirlo como nacido el 24 de agosto de 1958. Su entrada en el Ejército le va a abrir la posibilidad de escribir, así como el acceso a bibliotecas en las cuales encontrará obras de autores extranjeros. Es así como tiene contacto con una variada literatura e inicia la lectura de clásicos universales en traducción china, entre las cuales le impresionará especialmente la Biblia, en su vertiente literaria, a cuya lectura accede más tarde, en torno a los treinta años ${ }^{12}$. Varias décadas después, este libro será una inspiración fundamental en una de sus novelas: Los cuatro libros ${ }^{13}$.

Publicada en 2011 en Hong Kong y en Taiwán y traducida a diversas lenguas, entre ellas al español, el título hace una referencia muy directa a la tradición clásica china. Los Cuatro Libros es el nombre con el que se conocen cuatro textos del canon confuciano, a saber: Las Analectas o Diálogos, La doctrina del Justo Medio, La Gran Ciencia y Mencio. Dichos textos se

${ }^{11}$ En Yan Lianke, "Zou Xiang Xie Mu de Xiezuo" [Hacia una escritura para agradecer el aplauso final del público], Shou Huo, Número de Verano, (21 de julio 2017). Se ha tenido acceso a la versión de Weixin, y no indica número de página.

${ }^{12}$ Los datos biográficos proceden de conversaciones con Yan Lianke entre 2007 y 2018, tanto en China como en España. Consultar también Liang Hong, Yan Lianke Wenxue Nianpu [Cronología de la literatura de Yan Lianke], Shanghai, Fudan Daxue Chubanshe, 2015.

${ }^{13}$ Yan Lianke, Los cuatro libros, Barcelona, Galaxia Gutenberg, 2016. Traducción del chino al español de Taciana Fisac. Todas las citas textuales son de esta traducción.

Araucaria. Revista Iberoamericana de Filosofia, Política, Humanidades y Relaciones Internacionales, año $20, \mathrm{n}^{\circ} 40$. Segundo semestre de 2018. Pp. 137-158. ISSN 1575-6823 e-ISSN 2340-2199 doi: 10.12795/araucaria.2018.i40.06 
establecieron durante el neoconfucianismo como parte del canon que toda persona cultivada debía conocer. Yan Lianke en su novela trata de recordar a los miles de estudiosos, escritores y profesionales durante los años más duros del maoísmo, y los avatares que sufrieron desde el movimiento anti-derechista (1957), pasando por el Gran Salto Adelante (1958) y los tres años de grandes hambrunas que siguieron (1959-61). La historia está entretejida a través de cuatro textos: "El niño del Cielo" es un relato bíblico de la creación y vida en un campo de reeducación para “derechistas”, centrado en el niño, el jefe de dicho campo. "El antiguo cauce" es una suerte de relato autobiográfico, narrado en primera persona, sobre la vida en el campo de la pluma de un escritor. "Notas sobre los criminales" es un informe sobre los comportamientos anti-revolucionarios de los "criminales derechistas" que viven en el campo de concentración, cuya redacción ha sido solicitada por las autoridades a dicho escritor. Por último, "El nuevo mito de Sísifo" es un breve ensayo filosófico sobre la actitud vital ante el sufrimiento. El inicio de la novela nos remite directamente al texto bíblico, si bien la primera frase parece haber resultado excesivamente chocante para algunos traductores ya que, a pesar de ser relativamente sencilla en el original chino, ha dado lugar a interpretaciones muy distintas:

Dadi he jiao, huilai le. 大地和脚, 回来了。(original chino)

La madre tierra y los pies habían regresado (traducción española)

Ses pieds ont foulé la terre, il est revenu (traducción francesa)

The great earth and the mortal path returned together (traducción inglesa)

Die Erde kehrte heim und mit ihr alle Kreatur (traducción alemana)

La traducción española es la más literal, mientras que la francesa, al personalizar la frase en una tercera persona, distorsiona el original y reduce la fuerza de la misma. Su correspondencia en español sería: "Sus pies han pisado la tierra, él ha regresado. Por su parte, la traducción inglesa y alemana han mantenido gran parte del sentido original, pero han omitido "los pies" y lo han sustituido en ambos casos por elementos que acentúan el carácter de mito cosmológico: mortal path (vereda mortal), en el caso inglés; mit ihr alle Kreatur (con ella todas las criaturas), en el alemán. Sin entrar en una valoración de por qué los traductores han modificado esta primera frase del texto, es cierto que la intención del autor en sus primeros párrafos trata de remitir al lector a una suerte de mito cosmogónico, en el cual resuenan los primeros capítulos de la Biblia: 
La madre tierra y los pies habían regresado.

Pasado el otoño, se extendían vastos e inmensos los campos y las llanuras, se balanceaban en desorden los hombres, insignificantes sobre la tierra. El punto negro de una estrella fue agrandándose poco a poco. Las casas de los campos de reformación dividieron el Cielo y la Tierra. Entonces los hombres las habitaron. Y así se hizo. En las palmas de sus manos, la tierra sostenía los pies que habían regresado. [...] Los pies del niño danzaban al caer el sol. El calor quemaba los pies; quemaba los pechos y las espaldas. Los hombres se golpeaban contra el calor. El calor apretaba a los hombres. Las casas del campo de re-formación, los negros ladrillos y las negras tejas, sumamente envejecidos, acumulaban la luz de meses y años del caos primigenio, y en los extensos campos se dividieron el Cielo y la Tierra. Los hombres entonces las habitaron. Y así se hizo. [...]

El niño regresaba, la tierra sostenía los pies en las palmas de sus manos. Las puertas del campo de re-formación estaban desiertas y abiertas de par en par. Él tocó el silbato. El silbido quedó suspendido en el aire y, uno a uno, los hombres fueron llegando. Dijo Dios: "Haya un firmamento por entre las aguas. Que las aparte a unas de otras". E hizo el firmamento, apartando las aguas de debajo de las de arriba. Y así se hizo. Por encima del firmamento, el Cielo, por debajo del firmamento, la Tierra. La Tierra sostenía en sus manos a los hombres, en grupos aquí y allá.

Dijo el niño: "He regresado. Vengo de arriba, del municipio. Proclamo diez artículos".

Sin duda, cualquier lector familiarizado con el Antiguo Testamento puede identificar con nitidez la fuente de inspiración del autor. Ahora bien, llama la atención que la utilización de este recurso no es ni mucho menos novedosa en la literatura china. Por el contrario, nos remite a los textos más clásicos y, en especial, a una de las novelas maestras: Sueño en el Pabellón Rojo (Hongloumeng). Publicada treinta años después de la muerte de Cao Xueqin (1715-1764), en su versión de 120 capítulos, esta gran obra de la literatura universal ha tenido muy diversas lecturas e incluso ha dado lugar a una completa disciplina, conocida por el nombre de Rojología (hongxue). Los "rojólogos", en su mayoría, han tratado de utilizar la obra para reconstruir aquella época, ya que, a su entender, en esta novela hay rasgos biográficos del propio autor que, junto con innumerables detalles del contexto y la familia extensa en torno a la cual gira la trama, permiten una reconstrucción fiel del periodo en el cual fue escrita. El inicio de Sueño en el Pabellón Rojo también nos remite a una suerte de cosmogonía, fundamental para encuadrar el relato:

¿Saben ustedes, dignos lectores, cómo nació este libro? Su origen puede parecerles fantástico, pero no duden que, si se acercan a él con ánimo dispuesto, descubrirán que su lectura encierra mucho interés y puede ser de gran provecho. $[\ldots]$ 
Cuando la diosa Nüwa necesitó rocas para reparar la bóveda celeste acudió al Acantilado de lo Insondable, en la Montaña de la Inmensa soledad, con la intención de fundir treinta y seis mil quinientos y unos bloques de piedra, [...] El sobrante lo abandonó al pie del Pico de la Creta Azul. Aunque parezca extraño, aquella roca, después de ser templada por el fuego, había cobrado una esencia trascendental. [...].

Cierto día, mientras la roca se lamentaba de su suerte, vio venir a lo lejos a dos monjes, uno budista y otro taoísta, de porte imponente y apariencia distinguida. Se le acercaron y allí mismo se sentaron a conversar. Hablaron primero de montañas entre nubes, mares de bruma, dioses e ilusiones taoístas; luego, de las glorias y riquezas de los hombres. Al oír sus palabras, la roca se turbó con el profundo deseo de conocer ese mundo de los hombres y disfrutar ella también del placer y la felicidad ${ }^{14}$.

Este recurso narrativo no es característico de esta novela únicamente, sino un rasgo presente también en otras famosas obras clásicas chinas ${ }^{15}$. La utilización de esta estrategia, con una cosmogonía a modo de prólogo, ha dado lugar a una lectura de un conocido sinólogo norteamericano que ha tratado de subrayar los elementos arquetípicos y alegóricos del texto, en el caso concreto de Sueño en el Pabellón Rojo relacionándolos con elementos culturales chinos presentes en el Libro de los Cambios (Yijing), la cosmogonía del yin-yang y los denominados cinco agentes (wuxing $)^{16}$. Entre especialistas occidentales ha encontrado resonancia la importancia de lo simbólico en la concepción del texto, mientras que otros eruditos de origen chino han subrayado que son precisamente en novelas de carácter más realista donde el mito da materia y forma al relato ${ }^{17}$. Un crítico tan reputado como C. T. Hsia, profesor de origen chino en la Universidad de Columbia (EE UU), se muestra en desacuerdo con una interpretación que destaca fundamentalmente los elementos míticos de Sueño en el Pabellón Rojo. Por el contrario, según Hsia, en esta novela predominan los aspectos miméticos. De ahí que exista una "enorme cantidad de crítica contemporánea que considera Sueño en el Pabellón Rojo como una obra con una vital significancia social e ideológica en relación con la tradición china, en su conjunto, y con su tiempo, en particular"18. Parece, pues, plausible considerar que, desde un punto de vista tradicional, la utilización del mito y la

${ }^{14}$ Cao Xueqin, Sueño en el Pabellón Rojo, Barcelona: Galaxia Gutenberg/Círculo de Lectores, 2009; pp. 28 y 30. Traducción de Zhao Zhenjiang y José Antonio García Sánchez y revisión de Alicia Relinque.

${ }^{15}$ Sigue también este esquema Xiyou Ji [Viaje al Oeste]. Tradicionalmente atribuida a Wu Cheng'en (ca.1500-ca1582), y que se suele datar entre 1570 y 1580.

${ }^{16}$ Andrew H. Plaks, Archetype and Allegory in the "Dream of the Red Chamber", Princeton, Princeton University Press, 1976.

${ }^{17}$ Jean Levi, La Chine romanesque, Paris, Éditions du Seuil, 1995, pp. 211-219.

18 "The vast amount of contemporary criticism that regards Dream as a work of vital social and ideological significance in relation to the Chinese tradition as a whole and to its own time in particular", "Archetype and Allegory in the Dream of the Red Chamber. A Critique", [en C. T. Hsia. On Chinese Literature, New York: Columbia University Press, 2004], pp. 171-187. 
alegoría de hecho apuntan en la literatura china hacia una lectura de la realidad histórica y social.

Si bien es cierto que la definición de mito ha dado lugar a diversas interpretaciones, una de las más autorizadas nos indica que los mitos remiten a una historia sagrada como una "historia verdadera", en la cual se relatan acontecimientos que ocurrieron en un pasado lejano; el mito narra cómo una realidad (total o parcial) ha llegado a su existencia ${ }^{19}$. Los mitos de origen es frecuente que comiencen por una cosmogonía. En el caso concreto de China, es bien conocida la relación entre mito y escritura, por ejemplo en la invención de los caracteres, atribuidos al legendario Fu Xi y en su grafía a Cang Jie. La originalidad del escritor contemporáneo Yan Lianke radica en introducir una cosmogonía, al modo tradicional, utilizando un mito de la creación bíblica, más concretamente, una amalgama entre el primer capítulo del libro del Génesis y algunas ideas procedentes del libro del Éxodo. Pero, a su vez, entrelazando dichos versículos con uno de los mitos chinos de la creación del mundo, cuando un ser gigantesco, con el nombre de Pangu, divide Cielo y Tierra. En la tradición filosófica y de las religiones de China, el Cielo (Tian) es conocedor de todo, rige el mundo físico y moral, y se relaciona con el principio del yang, mientras que la Tierra $(D i)$ es el principio vivificador del universo, relacionado con el yin. Y el escritor entrelaza ambos mitos tan característicos del pasado chino y europeo. Como se ha indicado anteriormente, el desarrollo de la narración se articula en torno a cuatro textos, el último de los cuales, con el título de "El nuevo mito de Sísifo" vuelve a recurrir a un famoso mito europeo para cerrar la novela. Yan Lianke lo modifica también contraponiendo un Sísifo occidental y un Sísifo oriental. Ambos están condenados por los dioses a arrastrar una gran roca, pero su actitud vital es muy diferente:

En una cara de la montaña, Sísifo era el Sísifo occidental.

En la otra vertiente, Sísifo era el Sísifo oriental.

Todos los días Sísifo comenzaba en la cima de la montaña, empapado en una lluvia de sudor, empujando con fuerza la enorme roca hacia abajo y, nada más detenerse y sin un instante de respiro, la piedra, animada por una extraña fuerza, se ponía con suavidad de nuevo en movimiento de forma automática y a una velocidad constante, rodando hacia la cumbre de la montaña. Al día siguiente, Sísifo tenía que volver a empujarla con fuerza hacia abajo y al ponerse el sol la roca volvía a rodar de nuevo automáticamente hacia arriba [...]

Con la inversión del castigo, Sísifo experimentó sobre él el odio y la cólera de los dioses. Durante largo tiempo fue incapaz de adaptarse a aquel castigo y escarmiento invertidos. [...]

Sísifo se encontraba envuelto en aquella zozobra todos los días al amanecer, cuando se esforzaba exhausto por empujar la gigantesca roca que al anochecer volvía a rodar automáticamente hacia la cima. Un día tras otro, durante meses

${ }^{19}$ Mircea Eliada, Mito y realidad, Barcelona, Editorial Labor, 1991, capítulo I. 
y años, hasta que dejó de explotarle la cabeza de tanto pensar. Por segunda vez se acostumbró y se adaptó a empujar con fuerza hacia abajo en aquel ir y venir cíclico, sin tregua ni pausa; empezó a convertir aquella condena invertida en una tarea ejecutada a conciencia y con diligencia, a trabajar duro soportando los reproches, convirtiendo la pena en calma y armonía entre su cuerpo y espíritu. La adaptación mutua modificó la fuerza, la crueldad, el absurdo, incluso la muerte, la desesperanza y el silencio -como el de una lámpara al agotarse el aceite-, en crimen y castigo. Igual que anteriormente, con la visión del niño junto al camino, mientras Sísifo se esforzaba en voltear la enorme roca ladera abajo, un día, al tratar de alzar la vista por encima de la roca, vio al pie de la montaña vegetación, casas, pueblos, el humo de las cocinas y a unos niños jugando a la entrada de un templo budista.

Y la intención de Yan Lianke, al igual que en los textos tradicionales chinos es encuadrar el relato para darle carácter de historia real y verdadera. Los avatares sufridos por los "criminales" que se narran entre el mito inicial y el mito de cierre nos remiten a un tiempo y una realidad histórica muy concreta y tienen, utilizando las mismas palabras de C. T. Hsia, "una vital significancia social e ideológica". Pero este no es el único elemento de la narrativa de Yan que nos remite a la tradición china. Por ejemplo, los personajes de sus novelas se caracterizan por su modo de actuar; Yan no se adentra en su psicología ni describe su mundo interior para identificarlo. Es sobre todo el comportamiento social de los personajes el que los retrata y define. Encontramos rasgos semejantes en una de las primera novelas clásicas chinas: Romance de los Tres Reinos (Sanguo Zhi Yanyi). Este texto del siglo XIV está atribuido a Luo Guanzhong y cuenta con múltiples personajes que son caracterizados por su actuación pública. Se trata de una suerte de figuras tipo que, concretamente en esta primera novela clásica de gran extensión, estructuran su actuación en relación con diversos conflictos ${ }^{20}$. Al hilo de esta tradición discurren también los episodios de Los cuatro libros de Yan Lianke, en donde el rol se torna mucho más importante que el propio personaje y, por tanto, no se le otorga un nombre propio, se le asigna uno genérico en relación con su profesión. Los protagonistas de esta novela son el niño, el profesor de religión, el escritor, la música, el técnico del laboratorio, y otros muchos sin nombre, cuyos rasgos van revelándose en su manera de actuar.

Otros elementos en la novela que nos remiten a la literatura clásica son la alusión a poemas famosos y una prosa poética en la que está presente la mejor tradición china:

\footnotetext{
${ }^{20}$ Wilt Idema y Lloyd Haft, A Guide to Chinese Literature, Ann Arbor, The University of Michigan, 1997, pp. 198-203.
} 
...esa noche escuché un suspiro de la luna y un rumor de la tierra distintos a los habituales. No sabía si estábamos en la primera o en la segunda mitad del mes, tampoco me había fijado en si en el exterior de la choza la luna estaba menguante o creciente. Justo me disponía a dormir y penetró en mi oído el imperceptible rumor de un grillo trepando bajo la almohada. Levanté la cabeza y desapareció. Me apoyé sobre la almohada y el sonido volvió al interior de mi oído como una corriente de agua desbordada. Dejé a un lado la almohada, aparté las hierbas del camastro con objeto de apoyar la oreja directamente sobre el suelo y escuché los ruidos del movimiento a la carrera de las plantas de trigo y las raíces de las hierbas, procedentes del campo de trigo bajo la arena, como si se estuviera produciendo una pelea con un tira y afloja, y los brotes de trigo y las raíces de las hierbas estuvieran enzarzados en una discusión bajo tierra. [...] Aquel murmullo, levemente agudo y violáceo, era como el crujido del bambú al brotar hacia el exterior por entre las rendijas de las piedras en una noche silenciosa ${ }^{21}$.

Aparece aquí la omnipresente contraposición y complementariedad de los elementos: el cielo y la tierra, arriba y abajo, dentro y fuera. Además, los sentimientos y las emociones humanas se funden con la naturaleza y se describen mediante sonidos, olores, sabores, colores y texturas. Todo ello es característico de la poesía clásica de tiempos muy tempranos y forma parte del legado más rico de la literatura china. Además, a lo largo de la novela no faltan las alusiones a símbolos fundamentales de la cultura china, como es el impetuoso río Amarillo. Yan Lianke se recrea en el ciclo de la agricultura y utiliza bellas alegorías de la sangre, el sudor y las lágrimas derramadas por los campesinos en sus tierras y cultivos. El análisis de todos estos aspectos poéticos merecería un extenso capítulo aparte.

\section{Del realismo socialista al realismo del espíritu}

El realismo socialista (shehui xianshizhuyi) es el marco teórico literario por excelencia del periodo maoísta, entre 1949 y 1976. Su conceptualización tiene también un origen europeo. Son bien conocidas algunas de las discusiones de Engels en las que planteaba cuestiones básicas y contradicciones del realismo socialista: la relación entre literatura y compromiso político (Tendenz) y la caracterización de personajes "tipo", en circunstancias típicas de verosimilitud"2 Por su parte, la definición del realismo socialista que finalmente se concreta entre los escritores soviéticos en 1934 acentúa el compromiso político: "una representación verdadera e históricamente concreta de la realidad en

21 Yan Lianke, Los cuatro libros, p. 225.

22 D. W. Fokkema y E. G. Ibsch, Teorías de la literatura del siglo XX (IV edición), Madrid, Ediciones Cátedra, 1992, pp. 110-111.

Araucaria. Revista Iberoamericana de Filosofia, Politica, Humanidades y Relaciones Internacionales, año 20, $\mathrm{n}^{\circ} 40$. Segundo semestre de 2018. Pp. 137-158. ISSN 1575-6823 e-ISSN 2340-2199 doi: 10.12795/araucaria.2018.i40.06 
su desarrollo revolucionario" 23 . Esas mismas contradicciones inherentes al nacimiento de este marco teórico de la literatura se van a trasladar a China, si bien, moldeándose a partir de las premisas que Mao Zedong dictaría los días 2 y 23 de mayo de 1942, en una conferencia que se considera el vademécum de la creación literaria de este periodo. Queda así plasmada la idea de la inseparabilidad entre la literatura y la práctica política ${ }^{24}$.

La apertura acaecida en los años 80 del pasado siglo XX en China reabre de nuevo una discusión sobre el realismo (xianshizhuyi) en la literatura, al tiempo que modifica los límites impuestos anteriormente por el realismo socialista. Sin embargo, las reformulaciones, además de recoger aspectos de la tradición inmediata, no pueden escapar al hecho de que la utilización del sufijo "-ismo" (zhuyi) ha tenido generalmente un trasfondo marcadamente ideológico ${ }^{25}$. Y así, las distintas discusiones sobre el realismo, que con matices y variaciones continúa hasta nuestros días, no pueden escapar a dicho posicionamiento político. En este contexto, diversos críticos chinos van a denominar al escritor Yan Lianke con el apelativo de "gran maestro del realismo absurdo"26. Esta es una idea que el propio autor rechaza categóricamente ${ }^{27}$. Para contrarrestar dicha interpretación de su obra en el ámbito de lo absurdo, el propio Yan va a realizar una propuesta de marco teórico en el cual interpretar su obra: el realismo del espíritu o realismo divino (神实主义 shenshizhuyi). Con dicha propuesta también se posiciona respecto a otro importante debate del mundo literario chino sobre la responsabilidad social del escritor ${ }^{28}$.

Tanto en inglés como en francés se ha generalizado la traducción de shenshizhuyi como mythrealism (mito-realismo). Sin embargo, la discusión directa con Yan Lianke permite concluir que no se ajusta a su idea original y sería mucho más apropiada la traducción de spirit(s)realism. En chino, el carácter shen 神 se puede traducir, entre otras cosas por "espíritu” o "espíritus", "dioses" o "divinidad". Además, al combinarse con otros caracteres, adquiere otros significados. Así, shenhua 神话 es "mitología", "mito" o "leyenda",

${ }^{23}$ D. W. Fokkema y E. G. Ibsch, op. cit., p. 111.

${ }^{24}$ Los cambios del realismo socialista en China han sido detalladamente estudiados en D. W. Fokkema, Literary Doctrine in China and Soviet Influence 1956-1960, The Hague, Mouton \&Co, 1965. Y Mao Tse-tung, "Intervenciones en el Foro de Yanan sobre Arte y Literatura”, pp. 99-145 [en Escritos sociológicos y culturales, Barcelona, Editorial Laia, 1977].

25 Véase Ivo Spira, A Conceptual History of Chinese -Isms. The Modernization of Ideological Discourse, 1895-1925, Leiden y Boston, Brill, 2015, en especial el capítulo 3.

${ }^{26}$ Entre otros artículos que califican como "realismo del absurdo" la obra de Yan, véase, Yang Zhiyue y Zhou Chunying, "Cong Huangdan de Zhenshi Dao Zhenshi de Huangdan: Lun Yan Lianke Xiaoshuo Shouhuo de Chuangzuo Zhuti" [De la verdad del absurdo al absurdo de la verdad: sobre el motivo creativo en la novela Shouhuo de Yan Lianke], Mingzuo Xinshang, Vol. 1 (2016), pp. 56-57.

${ }^{27}$ Así me lo ha manifestado personalmente Yan Lianke en conversaciones diversas. Véase también una entrevista con motivo de la concesión del Premio Kafka de Literatura en 2014: http://cul. qq.com/a/20140605/008839.htm [acceso el 24 de mayo de 2018].

${ }^{28}$ Laifong Leung, "Yan Lianke. A Writer's Moral Duty”, Chinese Literature Today, Winter/Spring (2011), pp. 73-79.

Araucaria. Revista Iberoamericana de Filosofía, Política, Humanidades y Relaciones Internacionales, año 20, $\mathrm{n}^{\circ} 40$. Segundo semestre de 2018. Pp. 137-158. ISSN 1575-6823 e-ISSN 2340-2199 doi: 10.12795/araucaria.2018.i40.06 
mientras que 精神 jingshen significa “espíritu”, “espiritual” o "mental”, entre otras acepciones, y en la filosofía china también "espíritu vital". Por su parte, shen qing 神情 significa “espíritu y afectos”. Al utilizar un cierto carácter de un modo no habitual, el autor quiere incluir el mayor número de matices y aumentar las posibles lecturas e interpretaciones. De hecho, con la invención de este término en chino se trata de englobar todas ellas. La traducción de shenshizhuyi como "mito-realismo" bien puede calificarse de sesgada. A partir de las conversaciones mantenidas con el autor, se considera más apropiada la de "realismo del espíritu" o "realismo divino". Dos son los textos en los que Yan Lianke expone de un modo extenso cuál es su propuesta al hablar de shenshizhuyi ${ }^{29}$. En las últimas treinta y siete páginas de un ensayo sobre la literatura, Yan Lianke desarrolla su propuesta de realismo del espíritu o realismo divino, que describe del siguiente modo:

El realismo del espíritu, a grandes rasgos, se podría explicar de un modo sencillo. A decir: el rechazo en la creación literaria de relaciones lógicas superficiales inherentes a la vida verdadera (zhenshi), la investigación de una suerte de verdad (zhenshi) "no existente", una verdad (zhenshi) que no se ve, una verdad (zhenshi) tapada por la realidad (zhenshi). El realismo del espíritu se distancia del realismo. Su relación con la realidad (xianshi) no tiene una causalidad directa con la vida, sino que reside en el espíritu de las personas -en las conexiones de las personas con las relaciones internas de las cosas y el espíritu de la realidad-, en el alma humana, el pensamiento y la opinión particular del creador asentada en la realidad (xianshi). ${ }^{30}$

En el texto anterior, el término zhenshi 真实 aparece en varias ocasiones. En el diccionario se puede comprobar que tiene el significado de "real, verdadero, auténtico". En el contexto del párrafo anterior se ha traducido por "verdad" o "verdadera" en todos los casos menos en uno, en el que se ha utilizado "la realidad". Yan se está refiriendo a la realidad real y verdadera, la auténtica realidad que está tras la realidad aparente. Yan enumera diversos canales o métodos que, a su entender, permiten acceder a la comprensión de aspectos reales y auténticos de la cotidianeidad social, a saber: la imaginación, la alegoría, el mito, la legenda, el sueño, lo ilusorio, junto con la variación y transferencia mágicas. La Biblia sería para él una relevante fuente primaria ${ }^{31}$.

${ }^{29}$ Yan Lianke, Faxian Xiaoshuo [Descubrir la novela], Tianjin: Nankai Daxue Chubanshe, 2011 y Yan Lianke y Zhang Xuexing, Wo de Xianshi Wo de Zhuyi [Mi realidad, mi ismo], Beijing, Zhongguo Renmin Daxue Chubanshe, 2011.

30 Yan Lianke, Faxian Xiaoshuo, p. 181.

${ }^{31}$ Este párrafo no aparece publicado en la versión china, solo en la versión francesa: À la découverte du roman, Arles: Edition Philippe Picquier, 2017. Yan Lianke me indicó que le había pedido a la traductora francesa la introducción de este párrafo que no aparece en la versión en chino. Dicho párrafo es algo más extenso. La traducción que se ha hecho del original chino, difiere de la francesa. Los paréntesis son del propio autor.

Araucaria. Revista Iberoamericana de Filosofia, Política, Humanidades y Relaciones Internacionales, año 20, $\mathrm{n}^{\circ} 40$. Segundo semestre de 2018. Pp. 137-158. ISSN 1575-6823 e-ISSN 2340-2199 doi: 10.12795/araucaria.2018.i40.06 
La conceptualización del realismo del espíritu surge en las últimas páginas de un ensayo en el que Yan Lianke hace un análisis de la novela realista, circunscrita fundamentalmente a la tradición europea del siglo XIX y su evolución en el XX. En su recorrido ofrece una teoría en la que va a desarrollar tres variantes explicativas: la causalidad absoluta (quan yinguo), la causalidad nula (ling yinguo) y la semi-causalidad (ban yinguo) ${ }^{32}$.

Para Yan, la literatura europea del siglo XIX es un ejemplo paradigmático de una época dorada de la literatura, encarnada en las obras de autores como Víctor Hugo, León Tolstoi o Dostoievski, por mencionar solo algunos de los que más repite. Ahora bien, dicha literatura también tiene unos límites, ya que en la obra de estos autores hay una causa para todo que, a su vez, implica una consecuencia. Es lo que Yan denomina la escritura de causalidad absoluta; en la misma existe una unidad y una equiparación total entre causa y efecto ${ }^{33}$. Se encuentra siempre una razón de ser de los acontecimientos y, por ello, la tarea del autor es dar luz a aquellas causas oscuras o escondidas en la vida corriente para que, mediante la selección de las palabras, la intriga, los detalles y los personajes, el lector las vaya descubriendo al hilo de la lectura de la narración. "Hombres, acontecimientos, objetos, tiempo, espacio, todo se desarrolla, se extiende y actúa en la causalidad absoluta" ${ }^{34}$. La primera función del realismo consistiría en sacar a la luz esa causalidad latente o escondida, para explicar la forma de actuar de los personajes. Es por eso, por lo que los protagonistas de la causalidad absoluta se podrían presentar como "seres sociales" y su experiencia sería colectiva. En ese sentido, la preocupación de un autor como Lu Xun sería la de proporcionar un arquetipo de ese "ser social" 35 .

Yan Lianke establece en 1912 el nacimiento de la novela moderna, encuadrada en lo que él denomina "causalidad nula", por ser esta la fecha en la cual escribe Kafka sus primeras obras. Yan distingue varios niveles en $L a$ metamorfosis de Kafka. Por una parte, el relato de la angustia de Gregorio Samsa, tras su transformación en insecto y la historia interna del propio cuerpo del protagonista (subsidiaria a la historia principal); por otra, el desarrollo de la historia secundaria (y a su vez principal) sobre el impacto que dicho evento tiene en el resto de los personajes y en la evolución de sus sentimientos. Kafka construye su relato en torno a una causa y un efecto, pero dicha causa ya no tiene su origen en la realidad humana verdadera; y a su vez, da lugar a un efecto que permite un espacio abierto para la creación. Por eso Yan utiliza la denominación de causalidad nula. Kafka se consideraría uno de los fundadores de la vanguardia al abrir un camino distinto y establecer una causalidad diferente en el relato, inventando un nuevo orden en el cual la historia, la trama y los

\footnotetext{
32 Yan Lianke, Faxian Xiaoshuo, p. 107.

33 Yan Lianke, op. cit., p. 92.

34 Yan Lianke, op. cit., pp. 94-95.

35 Yan Lianke, op. cit., p. 98.
}

Araucaria. Revista Iberoamericana de Filosofia, Política, Humanidades y Relaciones Internacionales, año 20, $\mathrm{n}^{\circ} 40$ Segundo semestre de 2018. Pp. 137-158. ISSN 1575-6823 e-ISSN 2340-2199 doi: 10.12795/araucaria.2018.i40.06 
personajes se desarrollan a partir de una causalidad nula. Se trata de un orden narrativo en el cual surge "el absurdo". Kafka sería "el fundador de la literatura moderna del siglo XX", en donde la causalidad nula llevaría a una suerte de agujero negro que permitiría a cada lector hacer una interpretación de la obra ${ }^{36}$. Así, mientras el realismo tradicional haría a los personajes más grandes que a los autores, en la literatura moderna sucedería exactamente lo contrario. Ahora se otorgaría al escritor el poder absoluto, el autor se liberaría de sus personajes, ya no sería siervo de sus héroes -como lo era, por ejemplo, Ana Karenina de Tolstoi-, sino que él mismo adquiriría un poder ilimitado. El autor dejaría de estar subordinado a sus héroes, aunque Yan también se cuestiona si no se convertiría así en vasallo de la alienación y del absurdo ${ }^{37}$.

Pero además de la causalidad absoluta y la causalidad nula, existiría una tercera variante desarrollada por autores de habla hispana como García Márquez, Vargas Llosa, Carlos Fuentes o Julio Cortazar: son los representantes de la semi-causalidad. Destaca sobre todo a García Márquez, a quien Yan atribuye una cuasiaparente posibilidad de causa-efecto. En su obra ve Yan el comienzo y desarrollo de una suerte de relación con lo razonable, que no es ni una causalidad absoluta ni una causalidad nula. García Márquez inventa una causalidad de lo imposible, una suerte de reconciliación entre la causalidad absoluta y la causalidad nula. La discusión sobre la causalidad está fundamentalmente referida a "cómo escribir" (zenme xie) y "sobre qué escribir" (xie shenme). En la causalidad absoluta los personajes son seres sociales (shehui ren) y su historia está ligada a la sociedad y a la historia; en la causalidad nula el ser social se convierte en un ser individual (geti). Con la propuesta de García Márquez y otros escritores latinoamericanos se produciría una suerte de fusión entre las experiencias previas de las literaturas del siglo XIX y XX; surge una nueva relación entre personajes literarios, historia y realidad social; una suerte de "abandono" de los personajes al modo moderno, sin perder el vínculo con la historia a la manera realista. En esa semi-causalidad, Yan Lianke encuadra a autores como Joseph Heller, Camus, Thomas Pynchon o Günther Grass, y considera que en las obras de todos ellos se halla un modo distinto de conocimiento del mundo ${ }^{38}$.

Yan Lianke diferencia varios tipos de realidad interna en el propio texto. A partir del siglo XX, escritores, teóricos y lectores establecerían un contrato fundamentado en el principio de la realidad interna del relato de ficción, y esta realidad interna, para Yan, tendría que ver con el alma y la conciencia de las personas. La realidad externa del relato sería la de los comportamientos reales de las personas y las cosas; en el relato del siglo

\footnotetext{
${ }^{36}$ Yan Lianke, op. cit., pp. 75-86. La cita textual está en la página 80.

37 Yan Lianke, op. cit., pp. 63-69.

38 Yan Lianke, op. cit., pp. 109-129.
} 
XIX se daría esa correspondencia con la realidad externa (historia, sociedad, familia). Como ejemplo paradigmático de una relación hacia el exterior, Yan resalta a Raskólnikov, el protagonista de Crimen y Castigo de Dostoyevski. El autor ruso inmortalizaría en dicho personaje la realidad interna del alma y la conciencia, pero en una estrecha causalidad con lo que ocurre en el exterior. Yan distingue entre la atención del realismo en el materialismo del mundo objetivo, cuando el relato está estructurado desde el exterior (circunstancias y sociedad) hacia el interior (alma), frente al modernismo que va en dirección contraria: la historia se articula del interior hacia el exterior y la atención se fija en el idealismo del mundo subjetivo. Ejemplos paradigmáticos de esta última forma de escribir serían Mrs Dalloway de Virginia Woolf, Ulises de Joyce y En busca del tiempo perdido de Proust. Para Yan Lianke las diferencias entre la novela del siglo XIX y XX se harían evidentes al lector con el surgimiento de una realidad interna que puede ser alegórica o simbólica, auténtica o fragmentada. Se produce así una nueva lógica en la relación causal; los personajes y la trama se fundamentan en el propio texto, sin ser expresión tangible de la realidad. Los actos, los gestos y la evolución de los personajes se desarrollan y perfeccionan por su relación con la realidad interna, que a su vez es la que controla y hace avanzar la historia. Ejemplo del equilibrio en esta realidad interna serían obras como Rebelión en la Granja de George Orwell, Tropico de Cáncer de Henry Miller, En el camino de Jack Krouack o Howl (Aullido) de Allen Ginsberg, las tres últimas pertenecientes a la Generación Beat norteamericana, de la pasada década de los cincuenta ${ }^{39}$.

El denominado flujo de la conciencia, la experiencia psicológica de la colectividad o de la humanidad serían manifestaciones distintas de esta causalidad interna que en su parcialidad, condicionalidad y técnica de escritura se convierten en una visión de la literatura y del mundo trasladadas a la escritura. En palabras textuales de Yan Lianke: "un medio de conocimiento del mundo" y "un sendero nuevo para acceder a la realidad" ${ }^{40}$. Y sería precisamente en el nacimiento de la escritura con causalidad interna del siglo $\mathrm{XX}$, con nuevos espacios y posibilidades, donde la novela china actual encontraría inspiración; aquí es donde la realidad del espíritu y la verdad del alma, en relación con los cambios y avances de la experiencia objetiva de la vida, darían lugar a una nueva forma de literatura: "el realismo del espíritu" o "realismo divino" (shenshizhuyi).

Este es el hilo que lleva a Yan Lianke a interpretar el marco teórico en el que encuadra su obra y la de algunos otros autores chinos. Y, por eso subraya también que la creación literaria ha de estar fuertemente arraigada en la propia realidad social de China:

\footnotetext{
39 Yan Lianke, op. cit., pp. 152-159.

40 Yan Lianke, op. cit., p. 173.
}

Araucaria. Revista Iberoamericana de Filosofía, Política, Humanidades y Relaciones Internacionales, año 20, $\mathrm{n}^{\circ} 40$. Segundo semestre de 2018. Pp. 137-158. ISSN 1575-6823 e-ISSN 2340-2199 doi: 10.12795/araucaria.2018.i40.06 
La literatura contemporánea, tras treinta años tomando como modelo las diversas escuelas y técnicas modernas occidentales, también ha comprobado, en ciertos momentos, una falta de aclimatación de las corrientes literarias occidentales con la experiencia local china, y ha tomado conciencia de que el nacimiento de cualquier nueva corriente literaria, independientemente del tiempo, no puede alejarse de la realidad de su época y de su cultura local ${ }^{41}$.

Con esta afirmación, Yan Lianke admite la importancia de la propia tradición literaria china y deja clara la existencia de una estrecha conexión entre su tiempo y su contexto en su propia creación.

\section{A modo de conclusión: La literatura europea como modelo y subversión política}

Toda la teoría de la causalidad y del realismo del espíritu que se explica en los párrafos anteriores fue desarrollada principalmente antes de 2011. Años más tarde, con motivo de una invitación de la Universidad de Ciencia y Tecnología de Hong Kong para impartir un curso de escritura creativa, Yan Lianke trata de profundizar en el análisis de la novela y el relato de los siglos XIX y XX con doce lecciones dedicadas a cada periodo ${ }^{42}$. Estructuradas a modo de capítulos, en cada una de dichas lecciones analiza algún aspecto (la historia, los personajes, el lenguaje, el estilo, el trasfondo histórico y otros), y proporciona un texto a modo de ejemplo. De nuevo, el repaso de los títulos seleccionados pone de manifiesto la preferencia por autores extranjeros, y en especial de representantes de la literatura europea, con la mención de Goethe, Émile Zola, Chekhov, Guy de Maupassant, Gogol, Thomas Hardy y Alphonse Daudet; Mark Twain, "Jack London" y O. Henry en el caso de la literatura norteamericana; y Shen Congwen y Mori Ōgai, para la china y japonesa, respectivamente. Es decir, siete autores europeos, tres norteamericanos, uno chino y uno japonés. Por su parte, en las lecciones sobre la literatura del siglo XX aparecen también mayoritariamente autores europeos: Kafka, Claire Keegan, Gide, Mikhail Mikhailovich Zoshchenko; algunos norteamericanos: Hemingway, Mary Flannery O'Connor y Allen Ginsberg; y otros pertenecientes al continente americano de habla española y portuguesa: Juan Rulfo, Borges y Joao Guimaraes Rosa. La representación de la literatura asiática se circunscribe únicamente a Lu Xun y al japonés Yasunari Kawabata. Resulta también evidente la preferencia por autores masculinos. Sin entrar ahora en más detalle sobre el contenido de dichas lecciones, se puede afirmar que el canon literario europeo es para Yan Lianke un modelo por excelencia.

\footnotetext{
${ }^{41}$ Yan Lianke, op. cit., p. 188-189.

${ }^{42}$ Texto facilitado por el propio Yan Lianke en un correo electrónico el 10 de junio de 2017.
} 
La utilización del canon europeo como paradigma es indiscutible en sus escritos y clases teóricas sobre literatura, si bien, en su propia creación también existe otro uso distinto. En la novela Los cuatro libros, el canon literario europeo bien pudiera considerarse un modo de subversión política. En esta obra diríase que un buen número de clásicos europeos se convierten en una forma de protesta de los confinados en el campo de reeducación. Los "criminales" esconden los libros como si se tratara de grandes tesoros. Incluso el niño, jefe del campo, ordena requisarlos, aunque sin atreverse a destruirlos. Pese a no entender el significado de dichos libros, reconoce su valor y solo quema los volúmenes repetidos. Entre los libros que requisa aparecen muchos escritores europeos: Shakespeare, Cervantes, Dante, Honoré de Balzac, Victor Hugo, Dumas, Dickens, Goethe, Hegel, Prosper Mérimée, Dostoyevsky, Tolstoy y Stendhal ${ }^{43}$. También hay un lugar muy especial para la Biblia. De nuevo, solo se mencionan algunos autores chinos: los Siete Sabios de Wei y Jin, pertenecientes a las dinastías Tang y Song, Lu Xun, Pu Songling y Cao Xueqin.

El conocimiento de la literatura europea es indudable en Yan Lianke, aunque siempre indirectamente a través de traducciones al chino. Pero, ¿hasta qué punto bebe realmente de dicha tradición? Encuentra conscientemente inspiración en ella y aprovecha sus recursos, además de usarla de maneras que bien podrían interpretarse en clave de rebeldía. Lo cierto es que sus novelas mantienen fuertes elementos de la tradición china, incluso de un modo más explícito de lo que el propio autor reconoce. La genialidad y el carácter tan personal de entretejer la escritura convierten a Yan Lianke en el autor chino más innovador del panorama literario contemporáneo.

${ }^{43}$ La profesora Amelia Fernández resaltaba la inclusión de un canon europeo en Los cuatro libros en una conferencia que impartió en el Instituto Confucio de Madrid el 1 de diciembre de 2016. 


\section{Referencias bibliográficas:}

Cao, Xueqin, Sueño en el Pabellón Rojo, Barcelona, Galaxia Gutenberg/ Círculo de Lectores, 2009.

Eliade, Mircea, Mito y realidad, Barcelona, Editorial Labor, 1991.

Fokkema, D. W. y Ibsch, E. G., Teorías de la literatura del siglo XX (IV edición), Madrid, Ediciones Cátedra, 1992.

Fokkema, D. W., Literary Doctrine in China and Soviet Influence 1956-1960, The Hague, Mouton \& Co, 1965.

Hsia, C. T., On Chinese Literature, New York, Columbia University Press, 2004.

Idema, Wilt y Haft, Lloyd, A Guide to Chinese Literature, Ann Arbor, The University of Michigan, 1997.

Lee, Leo Ou-Fan, "The Politics of Technique: Perspectives of Literary Dissidence in Contemporary Chinese Fiction", pp. 159-190, en Jeffrey C. Kinkley (ed.) After Mao: Chinese Literature and Society 1978-1981, Cambridge (Massachusetts) y London, The Council on East Asian Studies/ Harvard University, 1985.

Leung, Laifong, "Yan Lianke. A Writer's Moral Duty", Chinese Literature Today, Winter/Spring (2011), pp. 73-79.

Leung, Laifong, Morning Sun. Interviews with Chinese Writers of the Lost Generation, Armonk, London, M. E. Sharpe, 1994.

Levi, Jean, La Chine romanesque, Paris, Éditions du Seuil, 1995.

Li, Sher-Shiueh, "The Art of Misreading: An Analysis of the Jesuit 'Fables' in Late Ming China” pp. 71-94 en Luo, Xuanmin y He, Yuanjian (eds.), Translating China, Bristol, Buffalo, Toronto, Multilingual Matters, 2009.

Liang, Hong, Yan Lianke Wenxue Nianpu, Shanghai, Fudan Daxue Chubanshe, 2015.

Lundberg, Lennart, Lu Xun as a Traslator: Lu Xun's translation and introduction of literature and literary theory, 1903-1936, Stockholm, Orientaliska Studier Stockholm University, 1989.

Luo, Xuanmin, "Ideology and Literary Translation. A Brief discussion on Liang Qi-chao’s Translation Practice”, pp. 124-134 en Luo, Xuanmin y He, Yuanjian (eds.), Translating China, Bristol, Buffalo, Toronto, Multilingual Matters, 2009.

Ma, Zuyi "History of Translation in China", pp. 373-392, en Chan Sin-Wai y David E. Pollard (eds), An Encyclopedia of Translation, Hong Kong, The Chinese University Press, 2001.

Mao, Tse-tung, Escritos sociológicos y culturales, Barcelona, Editorial Laia, 1977. 
Meng, Fanhua, Cheng, Guangwei y Chen, Xiaoming, Zhongguo Dandai Wenxue Liushi Nian, Beijing, Beijing Daxue Chubanshe, 2015.

Mo, Yan, Discurso con motivo de la concesión del Premio Nobel de Literatura, https://www.nobelprize.org/nobel_prizes/literature/laureates/2012/yanlecture.html. [acceso el 22 de mayo 2018].

Plaks, Andrew H., Archetype and Allegory in the "Dream of the Red Chamber", Princeton, Princeton University Press, 1976.

Spira, Ivo, A Conceptual History of Chinese -Isms. The Modernization of Ideological Discourse, 1895-1925, Leiden y Boston, Brill, 2015.

Yan, Lianke y Zhang, Xuexing, Wo de Xianshi Wo de Zhuyi, Beijing, Zhongguo Renmin Daxue Chubanshe, 2011.

Yan, Lianke, "Bingfei Wo de Zuopin Huangdan Er Shi Shenghuo Beshen Huangdan", en Da Hewang, http://cul.qq.com/a/20140605/008839.htm [acceso el 24 de mayo de 2018].

Yan, Lianke, "Zou Xiang Xie Mu de Xiezuo", Shou Hиo, Número de Verano, (21 de julio 2017).

Yan, Lianke, Faxian Xiaoshuo, Tianjin: Nankai Daxue Chubanshe, 2011. Edición en francés: A la découverte du roman, Arles: Edition Philippe Picquier, 2017.

Yan, Lianke, Los cuatro libros, Barcelona, Galaxia Gutenberg, 2016.

Yang, Zhiyue y Zhou, Chunying, "Cong Huangdan de Zhenshi Dao Zhenshi de Huangdan: Lun Yan Lianke Xiaoshuo Shouhuo de Chuangzuo Zhuti”, Mingzuo Xinshang, Vol. 1 (2016), pp. 56-57.

Zhou, Zuoren, Ouzhou Wenxue Shi, Beijing, Shiyue Wenyi Chubanshe, 2013. 